\title{
SISTEM PELATIHAN JARAK JAUH (PJJ) BALAI DIKLAT KEAGAMAAN MEDAN BERBASIS WEB MENGGUNAKAN LEARNING MANAGEMENT SYSTEM (LMS) MOODLE
}

\author{
M. Fajar Zain
}

\footnotetext{
Balai Diklat Keagamaan Medan JI. TB. Simatupang No. 122 Medan Telp. (061)8456256

E-mail: m.fajarzain@kemenag.go.id. Naskah diterima: 09 November2021 Naskah Direvisi: 12-20 November 2021

Naskah disetujui: 3 Desember 2021 Website Jurnal:

http://apicbdkmedan.kemenag.go.id.
}

\begin{abstract}
ABSTRAK
Proses Pelatihan di Balai Pendidikan dan Pelatihan Keagamaan (BDK) Medan diselenggarakan dengan metode klasikal, artinya proses pelatihan dapat terjalin dengan syarat adanya pertemuan antara panitia, peserta dan widyaiswara di kelas. Pandemi Covid-19 yang belum kunjung usai menyebabkan pelatihan dengan metode klasikal belum bisa dijalankan secara optimal. Oleh karena itu, dibangunlah sebuah metode pelatihan jarak jauh (E-Learning) sebagai solusi permasalahan tersebut. Untuk menunjang keberhasilan pelaksanaan pelatihan tersebut, diperlukan sebuah Sistem Pelatihan Jarak Jauh berbasis web pada proses pelatihan jarak jauh sebagai media antara panitia, peserta dan widyaiswara. Sistem berbasis web ini dirancang dengan menggunakan Learning Management System (LMS) Moodle versi 3.10.7. Metode perancangan sistem menggunakan pendekatan System Development Life Cycle (SDLC) dengan metode Waterfall. Sistem Pelatihan Jarak Jauh disarankan untuk disediakan petunjuk teknis penggunaan sistem tersebut.
\end{abstract}

Kata kunci: Sistem, Pelatihan Jarak Jauh, Web, LMS, Moodle

\begin{abstract}
The training process held by the Medan Religious Education and Training Center (BDK) is still carried out using the classical method, it means that training process can be established on the condition that there is a meeting between committee, participants and lecturers in a class. The Covid-19 pandemic, which has not ended until now, means that using classical training cannot be done optimally. Therefore, distance training method (E-Learning) was developed as a solution to the that problem. To support the successful implementation of the training, a web-based system for distance training process is needed as a media between committee, participants and lecturers. The Web-based system using Learning Management System (LMS) Moodle version 3.10.7. The method of system design uses the System Development Life Cycle (SDLC) approach with the Waterfall method. It is recommended that a Distance Training System be provided with technical instructions for using the system.
\end{abstract}

Keywords: System, Distance Learning, Web, LMS, Moodle

\section{PENDAHULUAN}

BDK Medan merupakan salah satu Unit Pelaksana Tugas Badan Litbang dan Diklat Kementerian Agama Republik Indonesia yang memiliki tugas pokok melaksanakan pelatihan Aparatur Sipil
Negara dalam rangka mendukung terlaksananya Sumber Daya Manusia Kementerian Agama Provinsi Sumatera Utara.

Proses pelatihan di Diklat Keagamaan Medan diselenggarakan dengan metode klasikal. Artinya, proses pelatihan dapat 
terjalin dengan syarat panitia, peserta dan widyaisawara bertemu atau bertatap muka dalam suatu kelas. Jika tidak memenuhi syarat tersebut, maka pelatihan tidak dapat dilaksanakan. Namun ada beberapa sebab pelatihan dengan metode tersebut kurang optimal, diantara adalah keterbatasan waktu, keterbatasan anggaran, urusan yang mendesak, dan lain sebagainya. Hal tersebut sangatlah tidak efisien karena keterbatasan tempat dan waktu sehingga peluang kesempatan peserta mengikuti pelatihan sangat kecil. Kontinuitas pandemi Covid-19 hingga saat ini juga menjadi sebab belum bisa terlaksana pelatihan klasikal secara optimal.

Untuk mengatasi masalah tersebut, maka dibangunlah sebuah metode pelatihan jarak jauh (E-Learning) sebagai solusi permasa lahan yang ada.

Perkembangan IT (Information Technology) yang sangat pesat membawa kebutuhan konsep dan mekanisme pelatihan yang mampu mengatasi hambatan waktu dan ruang karena memanfaatkan fasilitas jari-ngan melalui koneksi internet yang dapat diakses secara fleksibel.

Untuk menunjang keberhasilan pelaksanaan pelatihan tersebut, diperlukan sebuah Sistem Pelatihan Jarak Jauh berbasis web pada proses pelatihan jarak jauh sebagai media antara panitia, peserta dan widyaiswara. Sistem berbasis Web tersebut dirancang menggunakan Learning Management System (LMS) Moodle.

Kata sistem berasal dari bahasa latin (systema) atau bahasa Yunani (sustema) yang artinya unit elemen atau komponen yang saling berhubungan untuk memfasilitasi transfer materi, energi, atau informasi. Sistem disebut sebagai komponen tunggal yang saling berhubungan dan memiliki elemen penggerak. Sistem adalah kompleks yang utuh atau tersusun rapi, dan kombinasi atau kumpulan objek atau bagian membentuk satu kesatuan yang utuh atau kompleks. (Ramadhan, Ningrum, \& Yamin, 2016).
Desain dalam pengembangan perangkat lunak adalah konstruksi sistem yang memenuhi spesifikasi persyaratan fungsio-nal, memenuhi tujuan, secara implisit atau eksplisit memenuhi kinerja dan kebutuhan penggunaan sumber daya, dan memenuhi kendala proses desain biaya, waktu, dan peralatan (Rosa \& Shalahuddin, 2013).

Pelatihan adalah proses pendidikan jangka pendek dengan prosedur yang sistematis dan terorganisir bagi karyawan operasional untuk memperoleh pengeta huan dan keterampilan teknis untuk tujuan tertentu. (Hasibuan, 2012). Pelatihan adalah proses sistematik untuk mengubah perilaku karyawan ke arah peningkatan tujuan operasional (Henry, 2012) Menurut (Notoadmojo, 2003).

Pelatihan mengacu pada peningkatan keterampilan dan kemampuan karyawan yang melakukan pekerjaan atau tugas tertentu. Fokus pelatihan adalah pada tugas yang harus dilakukan. Pelatihan didasarkan pada pengetahuan dan sikap, tetapi umumnya menekankan keterampilan psikomotorik.

E-learning yang merupakan singkatan dari electronic learning merupakan jenis pendidikan dan pembelajaran baru yang menggunakan media elektronik khususnya internet sebagai sistem pembelajarannya. Elearning adalah proses pembelajaran jarak jauh yang menggabungkan prinsip dan teknologi proses pembelajaran (Chandra wati, 2010)

Internet adalah jaringan komputer terbesar di dunia, menghubungkan semua jaringan komputer (termasuk komputer itu sendiri) di seluruh wilayah dunia melalui media kabel atau nirkabel. Ini berarti bahwa ada banyak komputer yang saling terhubung di seluruh dunia di Internet. Organisasi dapat bertukar informasi secara internal atau eksternal dengan organisasi lain. Jaringan terdiri dari berbagai jenis komputer dan sistem operasi. Internet pada awalnya dikembangkan oleh Departemen Pertahanan 
Amerika Serikat untuk terhubung dengan para ilmuwan dan profesor universitas di seluruh dunia. Saat ini, internet dapat digunakan oleh siapa saja untuk mengakses segala informasi dan melakukan transaksi bisnis. (Kadir, 2014).

Web atau Website adalah kumpulan halaman situs, yang terangkum dalam sebuah domain atau subdomain, yang tempatnya berada di dalam World Wide Web (WWW) di dalam Internet. Halaman di web biasanya dokumen yang ditulis dalam format Hypertext Markup Language (HTML) yang selalu bisa diakses melalui HTTP, sebuah protokol yang mengirimkan informasi dari server situs web yang ditampilkan kepada pengguna melalui browser. Website dapat diartikan sebagai kumpulan halaman yang dapat menampilkan informasi data tekstual, data animasi, suara, video, atau semua kombinasi statis dan dinamis, yang masingmasing merupakan jaringan halaman yang terhubung (hyperlink) (Putra, 2015).

Learning Management System (LMS) adalah aplikasi atau perangkat lunak untuk mengelola pembelajaran online yang mencakup beberapa aspek yaitu materi, penempatan, pengelolaan, dan penilaian (Mahnegar, 2012).
Syarat penggunaan LMS dalam proses pembelajaran, pengajar dan peserta didik salah satunya adalah harus terkoneksi dengan jaringan internet yang memadai. Terdapat beragam fitur yang mendukung proses pembelajaran online, misalnya bahan ajar/tayang, forum diskusi, chat, kuis, tugas, informasi terkini terkait pelatihan, dan pengelolaan data pelatihan.

LMS yang dapat dimanfaatkan dalam proses pembelajaran diantaranya adalah Moodle, Edmodo, Google Classroom, dan lainlain.

Moodle (Modular Object-Oriented Dynamic Learning Environment) merupakan LMS yang bersifat web-based, yang berarti seluruh kegiatan pembelajaran dilakukan dengan mengakses website dengan bantuan web browser. LMS ini tersedia gratis (open source). Moodle bisa menjadi solusi cara belajar mengajar yang ekonomis namun efektif.

Moodle tidak hanya digunakan oleh lembaga pendidikan saja seperti sekolah, madrasah, kampus, dan lain sebagainya. Moodle juga banyak digunakan sebagai wadah karyawan disuatu perusahaan untuk mengembangan kompetensi seperti salah satu perusahaan terbesar dunia, Shell. (Niagahoster, 2020).

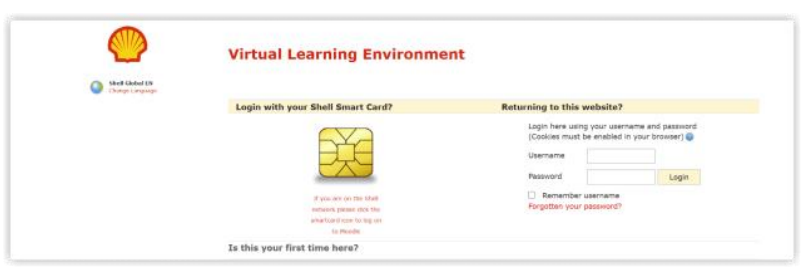

\section{Gambar 1. Shell}

\section{METODOLOGI PENELITIAN}

Sistem pelatihan jarak jauh (ELearning) dikembangkan melalui pendekatan metode waterfall yang terdiri dari beberapa tahapan yaitu analisa, perancangan/desain, imple-mentasi, serta pengujian.

1. Analisa sistem/analisa kebutuhan sistem, pada tahap ini adalah memastikan bahwa BDK Medan sudah memiliki fasilitas yang mendukung berjalannya sistem seperti web server, hosting, domain, web developer, dan regulasi yang mendukung.

2. Perancangan sistem, terdiri dari pembuatan alur, isi, serta tampilan grafis sistem. Dokumentasi yang dihasilkan pada tahapan ini antara lain perancangan Use Case Diagram dan Activity Diagram

3. Implementasi, pada tahapan ini adalah rancangan sistem diimplementasikan dalam sistem web berbasis Moodle. 
4. Pengujian dan evaluasi, yang bertujuan untuk mencari tahu apakah sistem yang sudah dibuat sudah berfungsi sesuai dengan tujuan yang dicapai. Pengujian ini menggunakan pendekatan Black Box
Testing guna menguji fungsionalitas sistem terdapat kesalahan atau tidak, hasil tersebut nantinya dievaluasi guna menciptakan sistem yang layak pakai dan berhasil guna.

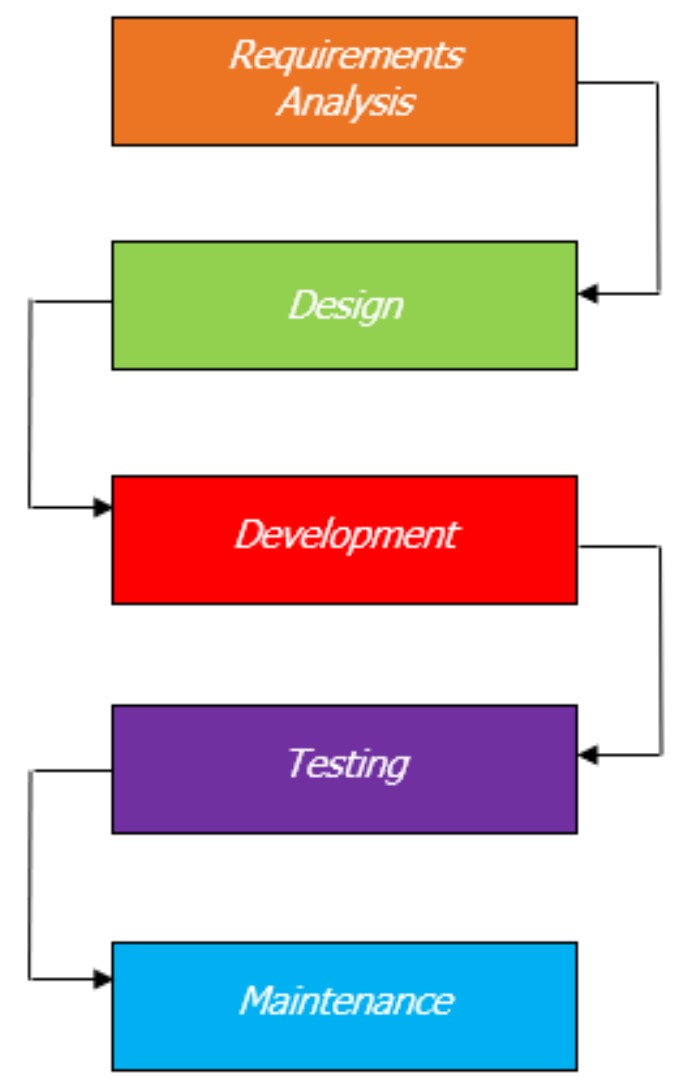

Gambar 2. Metode Waterfall

Untuk menguji validitas hasil desain, prototipe model perangkat lunak dibuat menggunakan alat atau bahan sebagai berikut.

1. Hardware (Perangkat Keras)

- Laptop Lenovo 81TK dengan spesifikasi Prosessor Core-i7-10510U, RAM 16 GB, HDD 1 TB SATA dengan Sistem Operasi Windows 1064 bit.

- Komputer Server Dell PowerEdge R740 dengan spesifikasi Prosessor Xeon Silver 4110, RAM 16 GB, HDD 2 TB SATA dengan Sistem Operasi Linux Debian 10 (Buster)

- Koneksi Internet

2. Software (Perangkat Lunak)

- Aplikasi klien SSH (PUTTY)
- Web Browser

- Web Server Apache 2.4.37

- Database Maria DB 10.3.12

- PHP 7.3.1

- Aplikasi LMS Moodle Versi 3.10.7

3. Informasi Pelatihan di BDK Medan

Data dikumpulan dengan metode berikut:

1. Observasi

Pengamatan kegiatan pelatihan di BDK Medan yang berhubungan dengan pembuatan Sistem Pelatihan Jarak Jauh

2. Wawancara

Keterangan atau pendapat mengenai Sistem Pelatihan Jarak Jauh kepada 
peserta, Widyaiswara dan Staf BDK Medan.

3. Kepustakaan yang berhubungan dengan penelitian.

\section{HASIL \& PEMBAHASAN}

\section{A. Analisa Sistem Berjalan}

\section{Observasi}

Hasil observasi dapat dilihat secara keseluruhan menunjukkan kelemahan pada sistem pelatihan yang ada di Balai Diklat Keagamaan Medan: 1) Pelatihan di BDK Medan masih dise lenggarakan secara klasikal, artinya proses pembelajaran antara peserta dan widyaiswara dilaksanakan di kelas. Jika pertemuan tidak terlaksana, maka pelatihan tidak dapat terlaksana pula.

1. Keterbatasan waktu juga dapat mengganggu proses pembelajaran. Hal ini menyebabkan diskusi yang kurang optimal antara peserta dan widyaiswara; 2) Pemberian tugas peserta yang kurang maksimal dikarenakan keterbatasan waktu pelatihan; 3) Keterbatasan anggaran pada penyeleng-garaan pelatihan secara klasikal yang mengakibatkan output alumni pelatihan setiap tahunnya tidak mengalami peningkatan secara signifikan.

Sistem pelatihan yang diseleng garakan secara klasikal dapat dilihat pada gambar flowchart berikut.

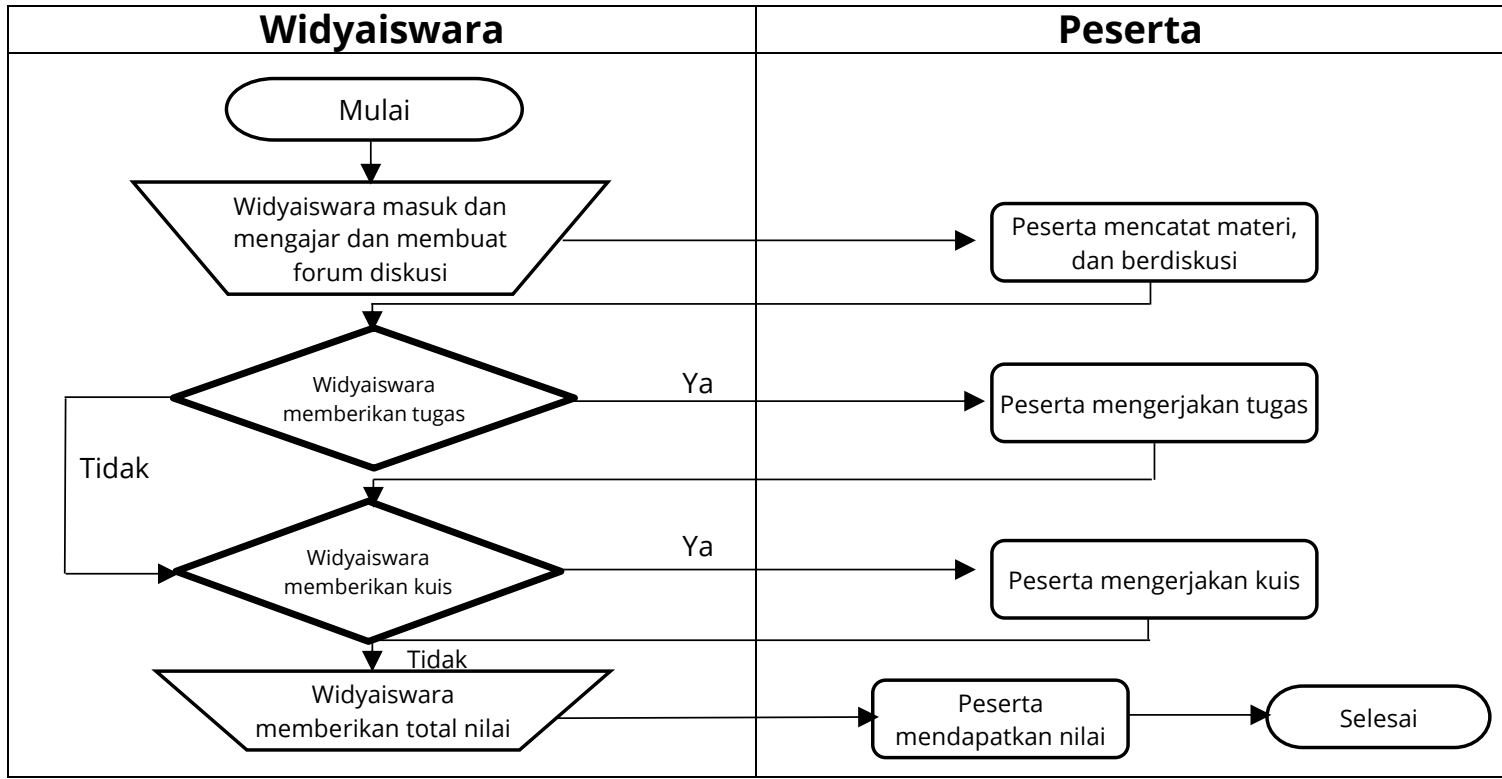

Gambar 3. Flowchart Sistem Pelatihan Klasikal

\section{B. Analisa Kebutuhan Sistem}

Berdasarkan pemaparan hasil observasi, dibutuhkan sebuah sistem yang dapat memecahkan masalah yang ada berdasarkan temuan pengamatan tersebut. Sistem yang dibutuhkan harus mampu menangani beberapa hal, seperti: 1) mendukung admin/panitia penyelenggara dalam kemudahan proses pelatihan tanpa harus bertemu langsung dan proses pelatihan pada model ini dapat dilakukan melalui penyediaan berbagai modul aktivitas pelatihan (modul pelatihan, modul video pembelajaran, modul bahan ajar, modul video conference, modul kuis, modul forum, modul tugas, dan modul evaluasi) agar pelatihan jarak jauh dapat berjalan dengan baik dan tersistem; 2) mendukung widyaiswara dalam kemudahan proses pelatihan tanpa harus bertemu langsung dan proses pelatihan pada model ini dapat dilakukan melalui berbagi materi pelatihan (file sharing), forum diskusi, tanya jawab langsung (chatting), video conference, pengerjaan kuis dan tugas.; 3) memberikan kemudahan kepada peserta untuk memperoleh materi yang akan diajarkan, dan berdiskusi pada Widyaiswara seputar substansi materi yang diajarkan; 3) 
Fleksibilitas waktu peserta untuk bertanya tanpa ikatan waktu tertentu.

Untuk memenuhi keperluan tersebut, maka diperlukan sebuah sistem yang bisa diakses dimana dan kapan saja melalui berbagai perangkat (komputer, smartphone) yang terhubung ke internet, baik oleh peserta maupun widyaiswara. Sistem yang dikembangkan hanya berperan sebagai pelengkap dari proses pelatihan tatap muka saja, tidak untuk menggantikan atau menghilangkanya dari prosedur pelatihan, serta meningkatkan jumlah output alumni yang signifikan selain berasal dari metode pelatihan klasikal.

\section{Analisa Sistem Usulan}

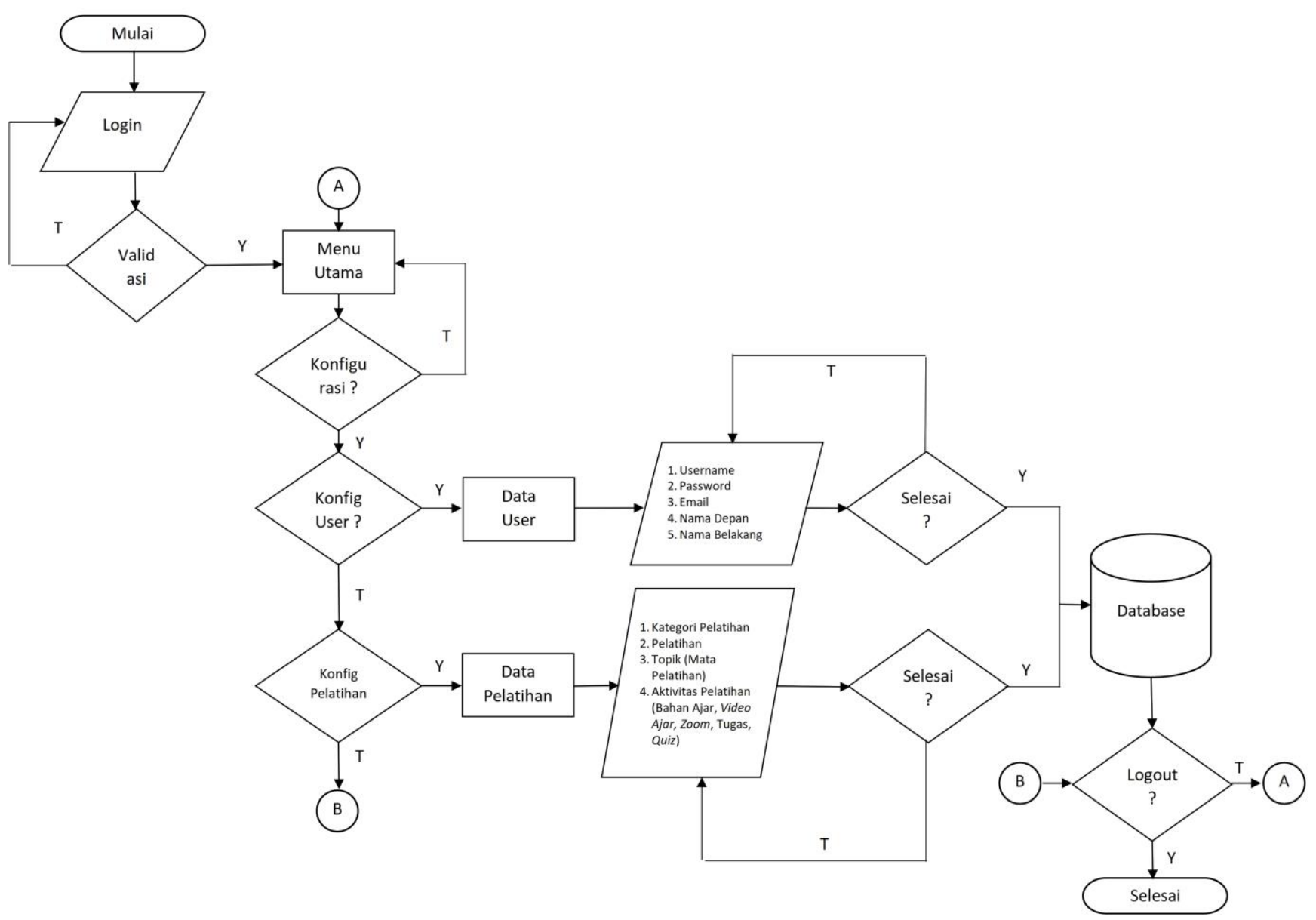

Gambar 4. Flowchart Sistem Usulan bagi Admin/Panitia temuan permasalahan dan berdasarkan analisa kebutuhan sistem yang telah dipaparkan adalah Sistem Pelatihan Jarak Jauh berbasis web yang bisa diakses oleh peserta, panitia dan widyaiswara dengan bantuan koneksi internet. Sistem tersebut diusulkan sebagai media atau pelengkap terlaksananya pelatihan jarak jauh yang akan diselenggarakan oleh BDK Medan.

Analisa sistem usulan pelatihan jarak jauh berbasis web digambarkan dalam bentuk flowchart yang dapat dilihat pada Gambar 4, Gambar 5, dan Gambar 6 


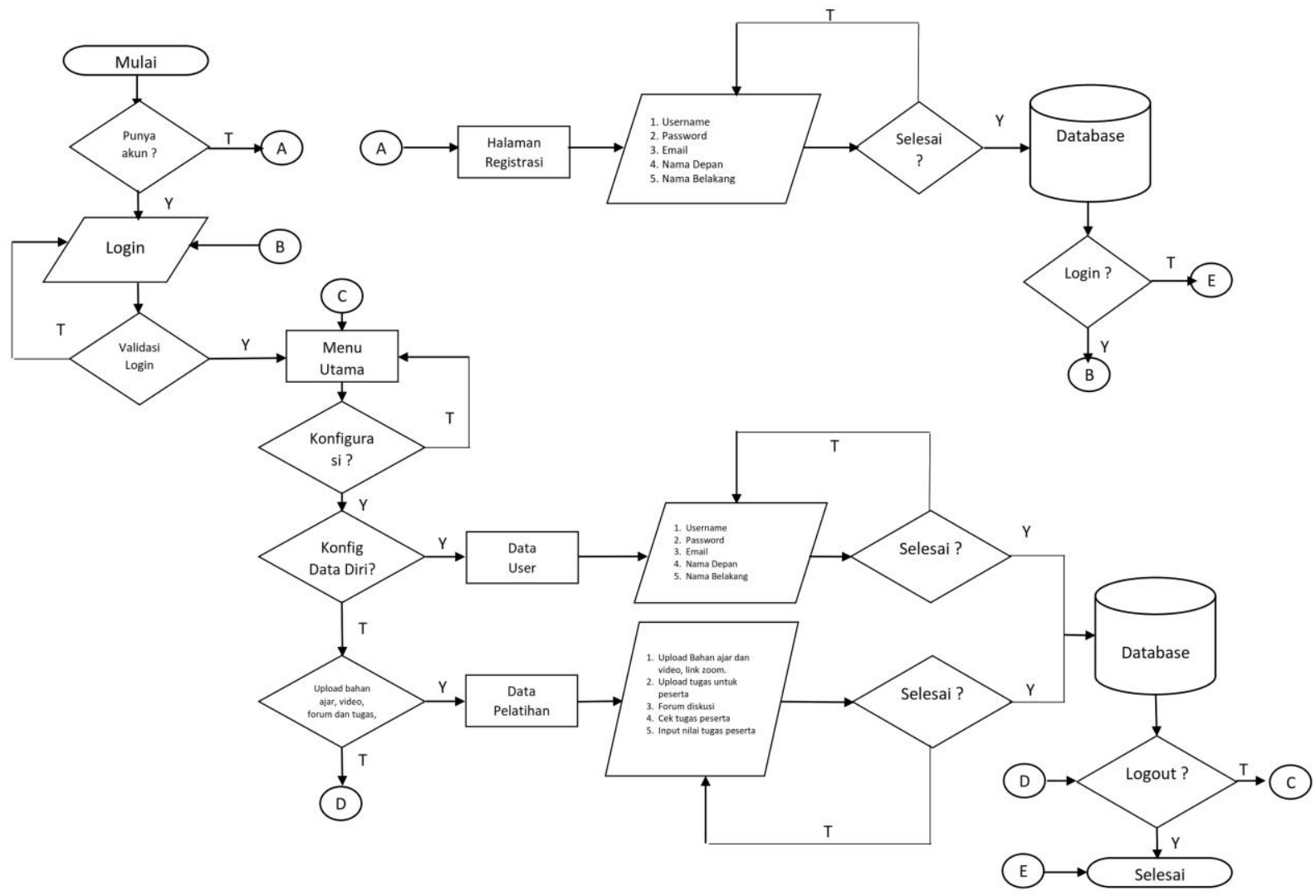

Gambar 5. Flowchart Sistem Usulan bagi Widyaiswara

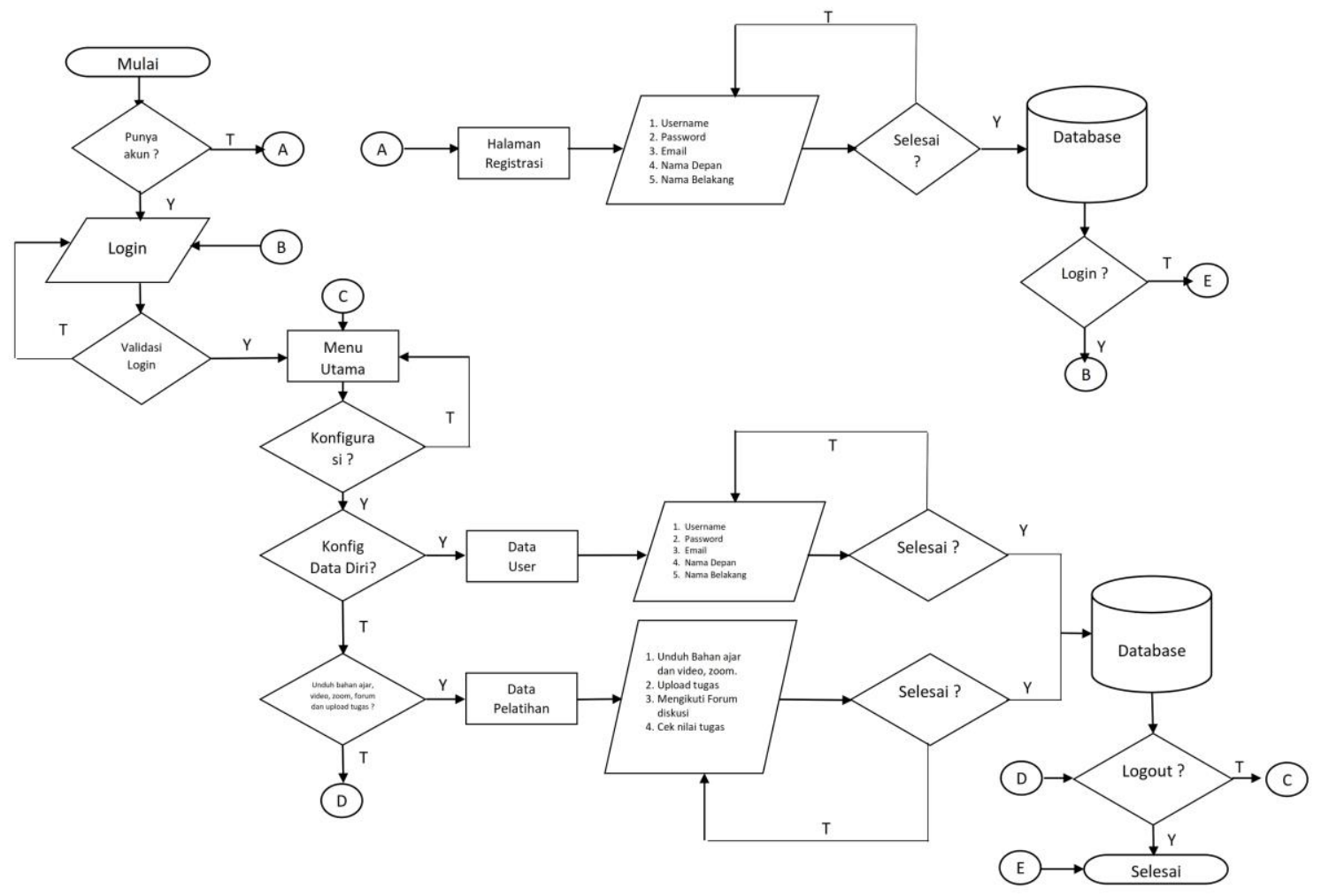

Gambar 6. Flowchart Sistem Usulan bagi Peserta

D. Perancangan Sistem
Setelah dilakukan analisa sistem usulan, dilanjutkan dengan proses 
perancangan sistem. Perancangan sistem pelatihan jarak jauh ditampilkan dengan bantuan use case diagram, yang dapat dilihat pada gambar 7 serta narasinya dapat dilihat pada keterangan yang dinarasikan pada tabel 1.

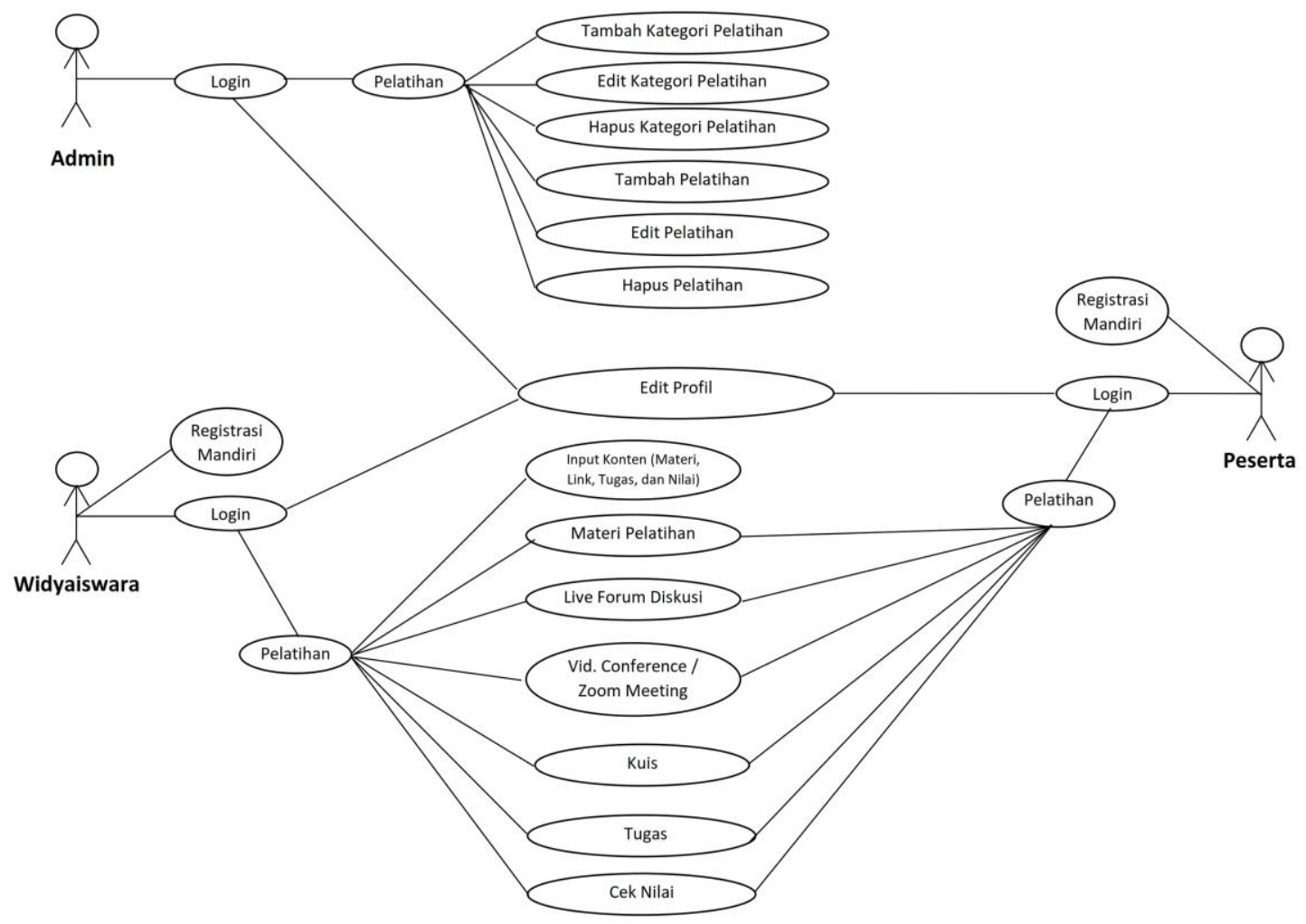

Gambar 7. Use Case Diagram

Tabel 1. Keterangan Use Case Diagram Sistem Usulan

\begin{tabular}{|c|l|l|l|}
\hline No & \multicolumn{1}{|c|}{ Use Case } & \multicolumn{1}{|c|}{ Aktor } & \multicolumn{1}{c|}{ Keterangan } \\
\hline 1 & Login (Masuk) & $\begin{array}{l}\text { Admin, Widyaiswara, } \\
\text { Peserta }\end{array}$ & $\begin{array}{l}\text { Admin, widyaiswara, dan peserta diperbolehkan } \\
\text { untuk login ke dalam sistem. }\end{array}$ \\
\hline 2 & Registrasi Mandiri & Widyaiswara, Peserta & $\begin{array}{l}\text { Widyaiswara dan peserta dapat mendaftarkan } \\
\text { diri untuk masuk ke dalam sistem (self } \\
\text { registration) }\end{array}$ \\
\hline 3 & Edit Profil & $\begin{array}{l}\text { Admin, Widyaiswara, } \\
\text { Peserta }\end{array}$ & $\begin{array}{l}\text { Admin, widyaiswara, dan peserta mengubah profil } \\
\text { (identitas diri) sesuai yang diinginkan }\end{array}$ \\
\hline 4 & Pelatihan & $\begin{array}{l}\text { Admin, Widyaiswara, } \\
\text { Peserta }\end{array}$ & $\begin{array}{l}\text { Admin, widyaiswara, dan peserta dapat melihat } \\
\text { pelatihan tertentu }\end{array}$ \\
\hline 5 & $\begin{array}{l}\text { Tambah kategori } \\
\text { pelatihan }\end{array}$ & Admin & $\begin{array}{l}\text { Hanya admin yang dapat menambahkan kategori } \\
\text { pelatihan. }\end{array}$ \\
\hline 6 & $\begin{array}{l}\text { Edit kategori } \\
\text { pelatihan }\end{array}$ & Admin & $\begin{array}{l}\text { Hanya admin yang dapat mengedit kategori } \\
\text { pelatihan yang sudah ditambahkan. }\end{array}$ \\
\hline 7 & $\begin{array}{l}\text { Hapus kategori } \\
\text { pelatihan }\end{array}$ & Admin & $\begin{array}{l}\text { Hanya admin yang dapat menghapus kategori } \\
\text { pelatihan yang sudah tidak diinginkan. }\end{array}$ \\
\hline 8 & Tambah pelatihan & Admin & $\begin{array}{l}\text { Hanya admin yang dapat menambahkan } \\
\text { pelatihan yang diinginkan. }\end{array}$ \\
\hline 9 & Edit pelatihan & Admin & $\begin{array}{l}\text { Hanya admin yang dapat mengedit pelatihan yang } \\
\text { sudah ditambahkan (termasuk aktivitas } \\
\text { pelatihan) }\end{array}$ \\
\hline
\end{tabular}




\begin{tabular}{|c|l|l|l|}
\hline No & \multicolumn{1}{|c|}{ Use Case } & \multicolumn{1}{|c|}{ Aktor } & \multicolumn{1}{c|}{ Keterangan } \\
\hline 10 & Hapus pelatihan & Admin & $\begin{array}{l}\text { Hanya admin yang dapat menghapus pelatihan } \\
\text { yang sudah tidak diinginkan. }\end{array}$ \\
\hline 11 & $\begin{array}{l}\text { Input Konten } \\
\text { (Materi, Link, Tugas, } \\
\text { dan Nilai) }\end{array}$ & Widyaiswara & $\begin{array}{l}\text { Hanya widyaiswara yang dapat menginput } \\
\text { konten suatu pelatihan (materi, link, tugas, dan } \\
\text { nilai peserta) }\end{array}$ \\
\hline 12 & Materi Pelatihan & Widyaiswara, Peserta & $\begin{array}{l}\text { Widyaiswara dan peserta dapat melihat beberapa } \\
\text { materi pelatihan dapat dapat diunduh }\end{array}$ \\
\hline 13 & Live Forum Diskusi & Widyaiswara, Peserta & $\begin{array}{l}\text { Widyaiswara dan peserta dapat melakukan forum } \\
\text { diskusi secara langsung }\end{array}$ \\
\hline 14 & Video Conference & Widyaiswara, Peserta & $\begin{array}{l}\text { Widyaiswara dan peserta dapat melakukan Video } \\
\text { Conference melalui aplikasi pihak ketiga (Zoom } \\
\text { Meeting) yang sudah tertera linknya di pelatihan } \\
\text { tertentu. }\end{array}$ \\
\hline 15 & Kuis & Widyaiswara, Peserta & $\begin{array}{l}\text { Widyaiswara dapat melihat kuis atau memeriksa } \\
\text { kuis tersebut serta mengerjakannya (testing), } \\
\text { peserta dapat melihat kuis dan mengerjakannya }\end{array}$ \\
\hline 16 & Cek Nilai & Widyaiswara, Peserta & $\begin{array}{l}\text { Widyaiswara dapat melihat dan memberikan nilai } \\
\text { peserta, peserta dapat melihat nilai yang sudah } \\
\text { diberikan oleh widyaiswara }\end{array}$ \\
\hline
\end{tabular}

\section{E. Perancangan Antar Muka}

Setelah sistem berhasil dirancang, maka selanjutnya adalah perancangan antar muka (interface) yang bertujuan untuk menghasilkan aplikasi yang eye-catching, nyaman dilihat oleh pengguna dan menarik, baik dari layout, warna, icon, dan lain sebagainya. Ketika diakses, pengguna akan dihadapkan dengan tampilan login terlebih dahulu. Pada tampilan tersebut, pengguna diwajibkan login (masuk) dengan menginput username dan password agar bisa menggunakan sistem pelatihan jarak jauh tersebut, jika pengguna lupa username ataupun password, terdapat menu "Lupa nama pengguna dan kata sandi Anda ?" untuk me-reset atau mengganti password nya dengan syarat memiliki email yang sudah terdaftar. Pengguna bisa melakukan registrasi mandiri jika pengguna belum memiliki akun, namun hal ini berlaku jika pengguna merupakan peserta pelatihan. Untuk tenaga pengajar atau widyaiswara akun sudah dibuat oleh admin sehingga hanya menunggu konfirmasi untuk mendapatkan akun. Tampilan login dapat dilihat pada gambar 8.

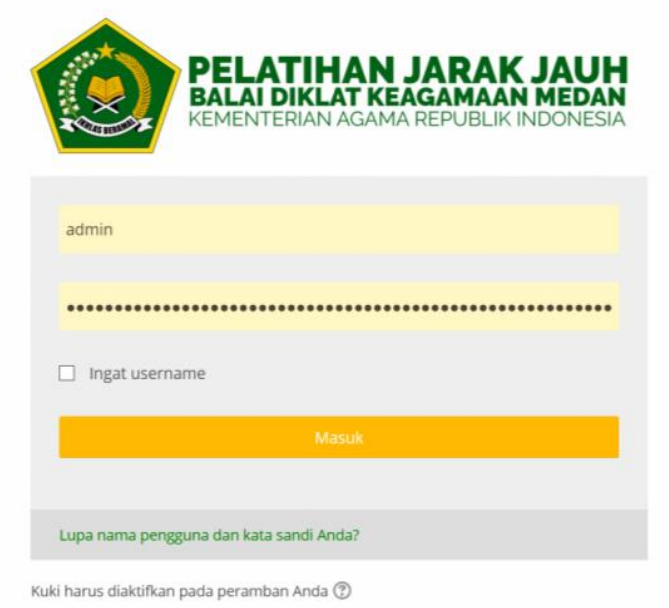

Gambar 8. Tampilan Login 
Tampilan registrasi mandiri (self registra tion) dapat dilihat pada gambar 9.

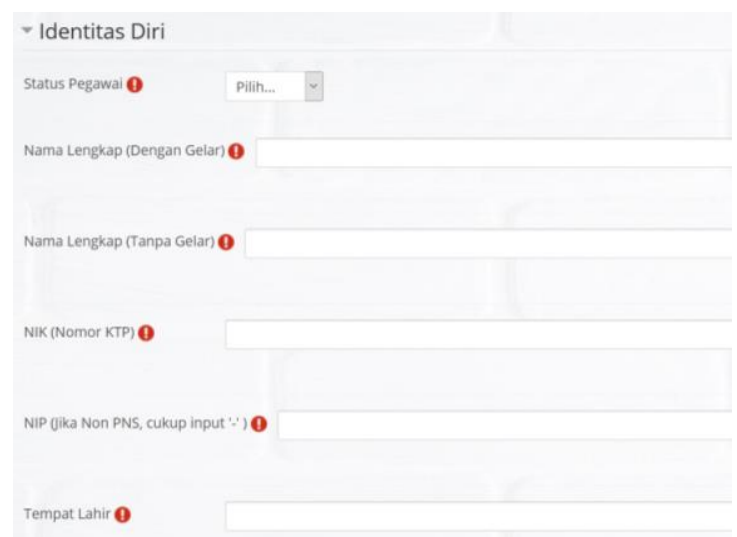

Gambar 9. Tampilan Registrasi Mandiri

Login berhasil, secara langsung sistem (dashboard) yang dapat dilihat pada gambar akan mengarah ke halaman utama 10.

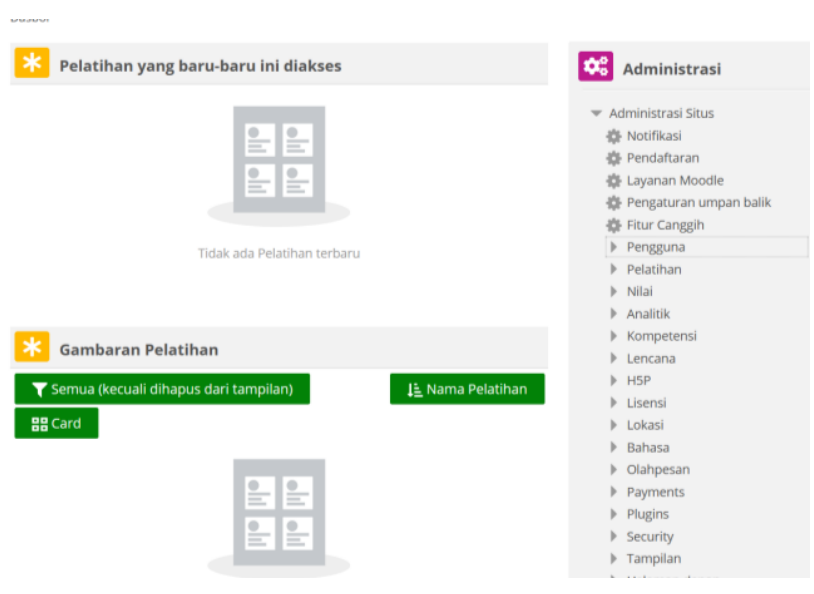

Gambar 10. Tampilan Dashboard

Tampilan kelas yang ada pada sistem akan terlihat seperti gambar 11 .

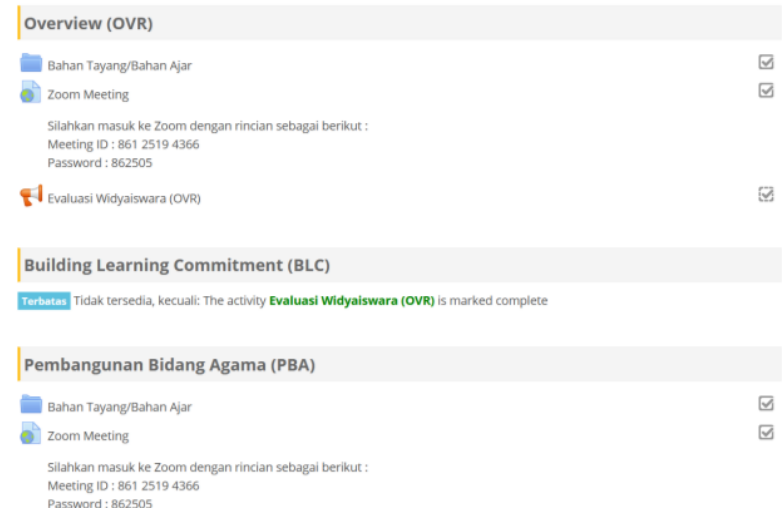

Gambar 11. Tampilan Kelas 
Pada gambar 11, terlihat ada beberapa mata pelatihan dan masingmasing pelatihan terdapat berbagai aktivitas yang wajib peserta selesaikan seperti unduh bahan ajar, evaluasi, tugas, dan lain sebagainya, dengan tujuan agar peserta bisa melanjutkan ke mata pelatihan selanjutnya sampai selesai seluruh aktivitasnya. Peserta tidak akan bisa mengikuti pelatihan selanjutnya jika aktivitas sebelumnya tidak dapat diselesaikan. Tanda checklist pada setiap aktivitas menandakan peserta sudah berhasil menyelesaikan aktivitas nya dengan baik. Widyaiswara akan mengunggah berbagai konten ke dalam kelas agar peserta bisa mengakses dalam hal pencarian bahan belajar peserta.

Proses penilaian tugas akan dinilai oleh widyaiswara melalui aplikasi sistem pelatihan tersebut. Tampilan review tugas dapat dilihat pada gambar 12 .

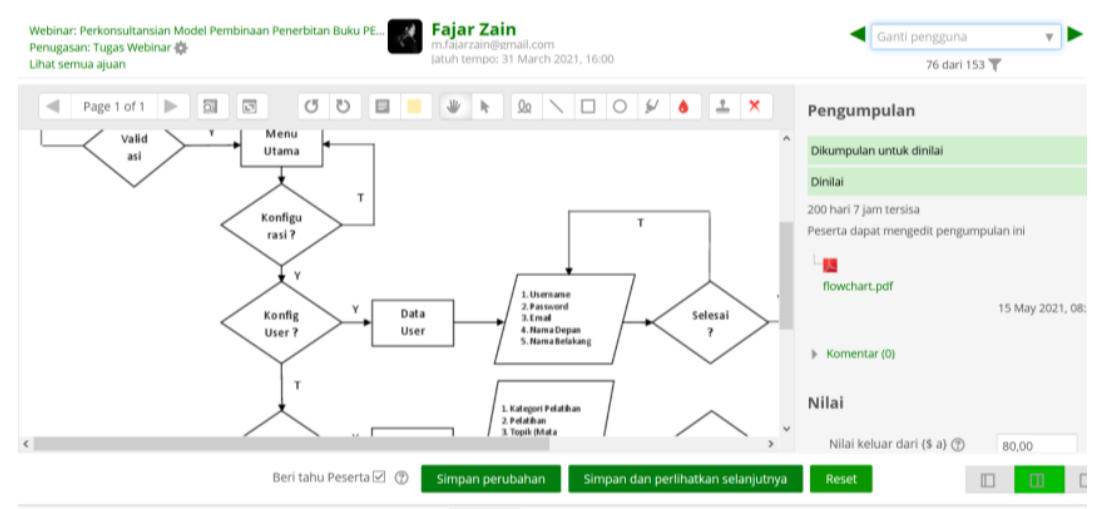

Gambar 12. Penilaian Tugas

Peserta juga nantinya akan mengerjakan kuis atau ujian berupa soal pilihan berganda dengan waktu yang secara sistem akan menghitung mundur berdasarkan batas waktu yang kita tentukan. Tampilan kuis atau ujian dapat dilihat pada gambar 13.

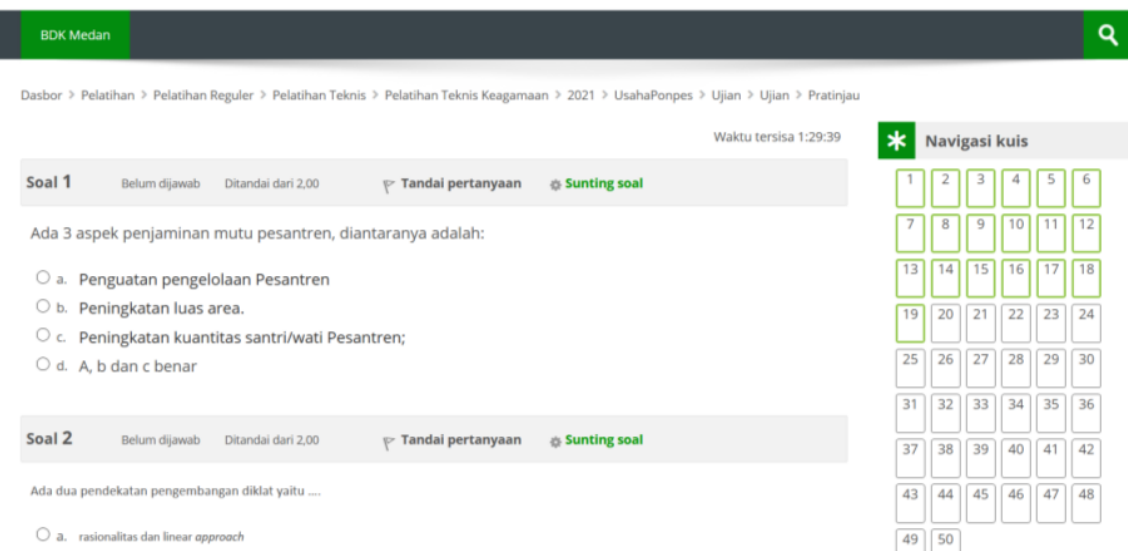

Gambar 13. Tampilan Kuis/Ujian

\section{F. Pengujian}

Langkah selanjutnya adalah melakukan pengujian yang bertujuan untuk menguji keberhasilan fungsionalitas sistem pelatihan jarak jauh agar meminimalisir kegagalan fungsi sebuah sistem pada saat digunakan oleh pengguna. Pengujian ini menggunakan pendekatan Black Box Testing 
yang merupakan metode pengujian sistem dengan meninjau fungsionalitas sistem. Hasil dari pengujian sistem dapat dilihat pada tabel 2, tabel 3, dan tabel 4.

Tabel 2. Pengujian Sistem Halaman Admin/Panitia

\begin{tabular}{|c|l|l|l|l|}
\hline No & \multicolumn{1}{|c|}{ Aktivitas } & \multicolumn{1}{|c|}{ Prosedur } & Hasil yang diharapkan & \multicolumn{1}{|c|}{ Kesimpulan } \\
\hline 1 & Login (Masuk) & $\begin{array}{l}\text { Masukkan username dan } \\
\text { password }\end{array}$ & $\begin{array}{l}\text { Sistem menuju Halaman } \\
\text { Dashboard }\end{array}$ & Berhasil \\
\hline 2 & Edit Profil & Pilih profil, ubah profil. & $\begin{array}{l}\text { Data diri yang diubah } \\
\text { tersimpan ke dalam } \\
\text { sistem }\end{array}$ & Berhasil \\
\hline 3 & $\begin{array}{l}\text { Tambah kategori } \\
\text { pelatihan }\end{array}$ & $\begin{array}{l}\text { Pilih pelatihan, tambah } \\
\text { kategori pelatihan }\end{array}$ & $\begin{array}{l}\text { Kategori pelatihan } \\
\text { tersimpan ke dalam } \\
\text { sistem }\end{array}$ & Berhasil \\
\hline 4 & $\begin{array}{l}\text { Edit kategori } \\
\text { pelatihan }\end{array}$ & $\begin{array}{l}\text { Pilih pelatihan, kelola } \\
\text { pelatihan / kategori }\end{array}$ & $\begin{array}{l}\text { Perubahan kategori } \\
\text { pelatihan tersimpan ke } \\
\text { dalam sistem }\end{array}$ & Berhasil \\
\hline 5 & $\begin{array}{l}\text { Hapus kategori } \\
\text { pelatihan }\end{array}$ & $\begin{array}{l}\text { Pilih pelatihan, kelola } \\
\text { pelatihan / kategori }\end{array}$ & $\begin{array}{l}\text { Kategori pelatihan } \\
\text { terhapus di dalam } \\
\text { sistem }\end{array}$ & Berhasil \\
\hline 6 & Tambah pelatihan & $\begin{array}{l}\text { Pilih pelatihan, tambah } \\
\text { pelatihan baru }\end{array}$ & $\begin{array}{l}\text { Pelatihan tersimpan ke } \\
\text { dalam sistem }\end{array}$ & Berhasil \\
\hline 7 & Edit pelatihan & $\begin{array}{l}\text { Pilih pelatihan, kelola } \\
\text { pelatihan / kategori }\end{array}$ & $\begin{array}{l}\text { Perubahan pelatihan } \\
\text { tersimpan ke dalam } \\
\text { sistem }\end{array}$ & Berhasil \\
\hline 8 & Hapus pelatihan & $\begin{array}{l}\text { Pilih pelatihan, kelola } \\
\text { pelatihan / kategori }\end{array}$ & $\begin{array}{l}\text { Pelatihan terhapus di } \\
\text { dalam sistem }\end{array}$ & Berhasil \\
\hline
\end{tabular}

Tabel 3. Pengujian Sistem Halaman Widyaiswara

\begin{tabular}{|c|l|l|l|l|}
\hline No & \multicolumn{1}{|c|}{ Aktivitas } & \multicolumn{1}{|c|}{ Prosedur } & Hasil yang diharapkan & \multicolumn{1}{|c|}{ Kesimpulan } \\
\hline 1 & Login (Masuk) & $\begin{array}{l}\text { Masukkan username dan } \\
\text { password }\end{array}$ & $\begin{array}{l}\text { Sistem menuju halaman } \\
\text { Dashboard }\end{array}$ & Berhasil \\
\hline 2 & Registrasi Mandiri & $\begin{array}{l}\text { Klik "silahkan daftar jadi } \\
\text { anggota baru", } \\
\text { masukkan identitas, } \\
\text { verifikasi lewat email, } \\
\text { login }\end{array}$ & $\begin{array}{l}\text { Pesan verifikasi masuk } \\
\text { ke email, sistem menuju } \\
\text { halaman Dashboard }\end{array}$ & Berhasil \\
\hline 3 & Edit Profil & Pilih profil, ubah profil. & $\begin{array}{l}\text { Data diri yang diubah } \\
\text { tersimpan ke dalam } \\
\text { sistem }\end{array}$ & Berhasil \\
\hline 4 & $\begin{array}{l}\text { Tambah materi, } \\
\text { forum, tugas, kuis, } \\
\text { dan aktivitas } \\
\text { lainnya }\end{array}$ & $\begin{array}{l}\text { Klik pelatihan, pilih mata } \\
\text { pelatihan, tambahkan } \\
\text { aktivitas }\end{array}$ & $\begin{array}{l}\text { Aktivitas suatu mata } \\
\text { pelatihan tersimpan ke } \\
\text { dalam sistem }\end{array}$ & Berhasil \\
\hline 5 & $\begin{array}{l}\text { Edit materi, forum, } \\
\text { tugas, kuis, dan } \\
\text { aktivitas lainnya }\end{array}$ & $\begin{array}{l}\text { Klik pelatihan, pilih mata } \\
\text { pelatihan, edit aktivitas }\end{array}$ & $\begin{array}{l}\text { Perubahan aktivitas } \\
\text { suatu mata pelatihan } \\
\text { tersimpan ke dalam } \\
\text { sistem }\end{array}$ & Berhasil \\
\hline 6 & $\begin{array}{l}\text { Hapus materi, } \\
\text { forum, tugas, kuis, } \\
\text { dan aktivitas } \\
\text { lainnya }\end{array}$ & $\begin{array}{l}\text { Klik pelatihan, pilih mata } \\
\text { pelatihan, edit aktivitas }\end{array}$ & $\begin{array}{l}\text { Aktivitas suatu mata } \\
\text { pelatihan terhapus di } \\
\text { dalam sistem }\end{array}$ & Berhasil \\
\hline
\end{tabular}




\begin{tabular}{|c|l|l|l|l|}
\hline No & \multicolumn{1}{|c|}{ Aktivitas } & \multicolumn{1}{c|}{ Prosedur } & Hasil yang diharapkan & \multicolumn{1}{c|}{ Kesimpulan } \\
\hline 7 & Tambah nilai & $\begin{array}{l}\text { Klik pelatihan, pilih mata } \\
\text { pelatihan, pilih tugas, } \\
\text { periksa, berikan nilai }\end{array}$ & $\begin{array}{l}\text { Nilai tersimpan ke dalam } \\
\text { sistem }\end{array}$ & Berhasil \\
\hline 8 & Edit nilai & $\begin{array}{l}\text { Klik pelatihan, pilih mata } \\
\text { pelatihan, pilih tugas, } \\
\text { periksa, berikan nilai }\end{array}$ & $\begin{array}{l}\text { Perubahan tersimpan ke } \\
\text { dalam sistem }\end{array}$ & Berhasil \\
\hline 9 & Hapus nilai & $\begin{array}{l}\text { Klik pelatihan, pilih mata } \\
\text { pelatihan, pilih tugas, } \\
\text { hapus nilai }\end{array}$ & $\begin{array}{l}\text { Nilai terhapus di dalam } \\
\text { sistem }\end{array}$ & Berhasil \\
\hline
\end{tabular}

Tabel 4. Pengujian Sistem Halaman Peserta

\begin{tabular}{|c|c|c|c|c|}
\hline No & Aktivitas & Prosedur & Hasil yang diharapkan & Kesimpulan \\
\hline 1 & Login & $\begin{array}{l}\text { Masukkan username dan } \\
\text { password }\end{array}$ & $\begin{array}{l}\text { Sistem menuju halaman } \\
\text { Dashboard }\end{array}$ & Berhasil \\
\hline 2 & Registrasi Mandiri & $\begin{array}{l}\text { Klik "silahkan daftar jadi } \\
\text { anggota baru", masukkan } \\
\text { identitas, verifikasi lewat email, } \\
\text { login }\end{array}$ & $\begin{array}{l}\text { Pesan verifikasi masuk } \\
\text { ke email, sistem menuju } \\
\text { halaman Dashboard }\end{array}$ & Berhasil \\
\hline 3 & Edit Profil & Pilih profil, ubah profil. & $\begin{array}{l}\text { Data diri yang diubah } \\
\text { tersimpan ke dalam } \\
\text { sistem }\end{array}$ & Berhasil \\
\hline 4 & Unduh materi & $\begin{array}{l}\text { Klik pelatihan, pilih mata } \\
\text { pelatihan, unduh materi }\end{array}$ & Materi berhasil diunduh & Berhasil \\
\hline 5 & Forum diskusi & $\begin{array}{l}\text { Klik pelatihan, pilih mata } \\
\text { pelatihan, klik forum diskusi }\end{array}$ & $\begin{array}{l}\text { Forum berjalan dengan } \\
\text { baik }\end{array}$ & Berhasil \\
\hline 6 & Video conference & $\begin{array}{l}\text { Klik pelatihan, pilih mata } \\
\text { pelatihan, klik link video } \\
\text { conference }\end{array}$ & $\begin{array}{l}\text { Sistem mengarah ke link } \\
\text { video conference }\end{array}$ & Berhasil \\
\hline 7 & Unduh tugas & $\begin{array}{l}\text { Klik pelatihan, pilih mata } \\
\text { pelatihan, pilih tugas, unduh } \\
\text { tugas }\end{array}$ & Tugas berhasil diunduh & Berhasil \\
\hline 8 & Upload tugas & $\begin{array}{l}\text { Klik pelatihan, pilih mata } \\
\text { pelatihan, pilih tugas, upload } \\
\text { tugas }\end{array}$ & Tugas berhasil di-upload & Berhasil \\
\hline 9 & Edit tugas & $\begin{array}{l}\text { Klik pelatihan, pilih mata } \\
\text { pelatihan, pilih tugas, ubah } \\
\text { tugas }\end{array}$ & $\begin{array}{l}\text { Perubahan tugas } \\
\text { tersimpan ke dalam } \\
\text { sistem }\end{array}$ & Berhasil \\
\hline 10 & Hapus tugas & $\begin{array}{l}\text { Klik pelatihan, pilih mata } \\
\text { pelatihan, pilih tugas, hapus } \\
\text { tugas }\end{array}$ & $\begin{array}{l}\text { Tugas terhapus di dalam } \\
\text { sistem }\end{array}$ & Berhasil \\
\hline 11 & Mengerjakan kuis & $\begin{array}{l}\text { Klik pelatihan, pilih mata } \\
\text { pelatihan, pilih kuis, kerjakan } \\
\text { kuis }\end{array}$ & $\begin{array}{l}\text { Kuis selesai dikerjakan } \\
\text { dan tercantum nilai }\end{array}$ & Berhasil \\
\hline 12 & Periksa nilai & $\begin{array}{l}\text { Klik pelatihan, pilih mata } \\
\text { pelatihan, pilih tugas, periksa } \\
\text { nilai }\end{array}$ & $\begin{array}{l}\text { Nilai tercantum di dalam } \\
\text { sistem }\end{array}$ & Berhasil \\
\hline
\end{tabular}

\section{G. Registrasi Domain}

Setelah melakukan pengujian, langkah selanjutnya adalah registrasi domain. Domain merupakan alamat website yang nantinya dituliskan pada address bar di browser untuk mengakses suatu sistem berbasis web. BDK Medan merupakan unit kerja pada instansi Kementerian Agama, 
sehingga domain yang dibutuhkan menggunakan subdomain.kemenag.go.id. Sesuai dengan Surat Edaran Nomor: 2597/SJ/B.VIII/3/HM.00/04/2018 tentang Tata Cara Penggunaan Subdomain kemenag.go.id, maka perlu ditindaklanjuti dengan melakukan beberapa proses yang harus diselesaikan berdasarkan surat edaran sebelum mengajukan registrasi domain. Setelah proses selesai, langkah selanjutnya adalah membuat surat pengajuan registrasi domain ke Biro Humas Data, dan Informasi (HDI) Kementerian Agama Republik Indonesia lewat aplikasi SIGAP (sigap.kemenag.go.id). Domain yang diusulkan untuk sistem pelatihan jarak jauh BDK Medan adalah pjjbdkmedan.kemenag.go.id. Beberapa waktu kemudian pihak Biro HDI membalas pengajuan tersebut dengan melakukan penetration testing (pentest) untuk menguji sekuritas sebuah sistem yang diajukan. Ketika sistem dinyatakan lulus pentest, maka pihak Biro HDI Kemenag RI melakukan pointing domain. Pointing domain merupakan proses mengarahkan domain yang diajukan ke IP website kita, sehingga ketika pengguna mengetik domain yang kita ajukan ke browser, maka sistem pelatihan jarak jauh BDK Medan yang akan muncul dan siap untuk digunakan. Hasil pentest Sistem Pelatihan Jarak Jauh BDK Medan menunjukkan tidak ada High atau Medium Risk yang terdapat pada website sehingga sekuritas sistem yang ada dinilai tidak mengkhawatirkan. Respon dari Biro HDI serta hasil pentest Sistem Pelatihan Jarak Jauh BDK Medan dapat dilihat pada gambar 14 dan 15.

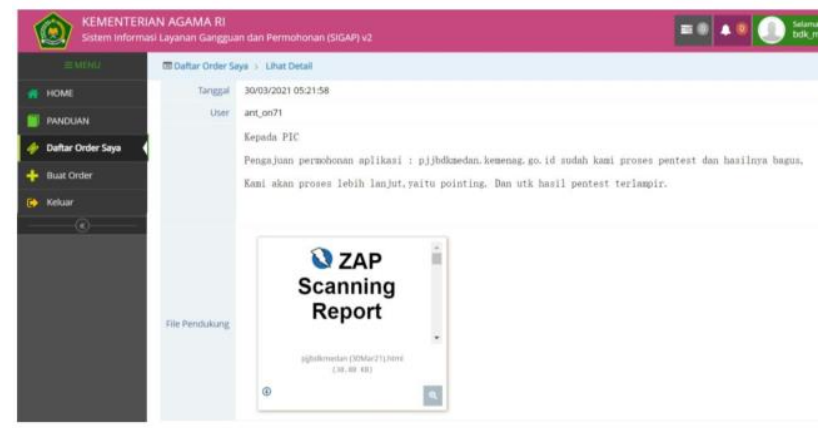

Gambar 14. Respon dari Biro HDI

ZAP Scanning Report

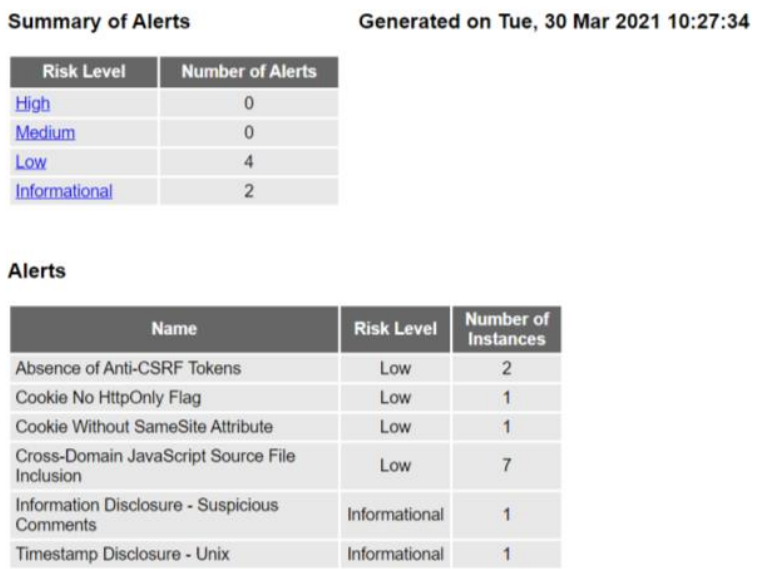

Gambar 15. Hasil Pentest Sistem PJJ BDK Medan 


\section{SIMPULAN}

Berdasarkan hasil dan pembahasan, maka diperoleh beberapa kesimpulan sebagai berikut: 1) penelitian ini menghasilkan sebuah Sistem Pelatihan Jarak Jauh BDK Medan berbasis Web menggunakan Learning Management System (LMS) Moodle untuk menunjang keberhasilan pelaksanaan Pelatihan yang dilaksanakan secara daring; 2) sistem Pelatihan Jarak Jauh BDK Medan sudah dapat diakses dengan alamat https://pjjbdkmedan.kemenag.go.id; penelitian ini hanya mencakup pengembangan sistem sampai sistem tersebut berjalan, sehingga perlu adanya penelitian lanjutan mengenai fitur-fitur tambahan yang mendukung pada LMS Moodle.

\section{SARAN}

Penelitian ini hanya mencakup pengembangan sistem sampai sistem tersebut berjalan dan diakses secara publik, sehingga perlu adanya penelitian lanjutan mengenai fitur-fitur tambahan yang mendukung pada sistem pelatihan jarak jauh seperti login terintegrasi (SSO), absensi online, konten pembelajaran terkini, hingga e-sertifikat.

\section{DAFTAR PUSTAKA}

Adelheid, A. (2015). Cara Mudah Bikin Website dan Promosi ke SEO. Yogyakarta: MediaKom.

Chandrawati, Sri Rahayu (2010). Pemanfaatan ELearning dalam Pembelajaran. Jurnal Cakrawala Kependidikan

Dharmawan, D. D. (2012). Pendidikan Teknologi Informasi dan Komunikasi. Bandung: Rosda.

Fathansyah. (2012). Basis Data. Bandung: Penerbit Informatika.

Henry, S. (2012). Manajemen Sumber Daya Manusia. Edisi 1. Yogyakarta: STIEYKPN.

Kadir, A. (2014). Pengenalan Sistem Informasi Edisi Revisi. Yogyakarta: Penerbit Andi.
Niagahoster (2020). Apa itu Moodle ? Panduan untuk Pemula, Diakses pada 12 April 2021, dari

https://www.niagahoster.co.id/blog/moo dle-adalah/

Notoadmojo. (2003). Manajemen Sumber Daya Manusia. Jakarta: Rineka Cipta.

Nugraha, A. P., \& Gunadhi, E. (2016). Penerapan Kriptografi Base64 Untuk Keamanan Url (Uniform Resource Locator) Website Dari Serangan Sql Injection. Jurnal Algoritma Sekolah Tinggi Teknologi Garut, 491.

Nurasiah. (2014). Perencanaan Pengembangan Sistem Informasi Pembayaran Uang Kuliah Dengan Metode SDLC Waterfall. Jurnal Teknologi dan Rekayasa, 72.

Pratama, I. P. (2014). Komputer dan Masyarakat. Bandung : Penerbit Informatika.

Pratama, I. P. (2014). Sistem Informasi dan Implementasinya. Bandung: Penerbit Informatika.

Putra, Y. I. (2015). 1 Jam Pasti Bisa Membuat Website Gratis Otodidak Tanpa Guru. Jakarta: Dan Idea.

Ramadhan, A., Ningrum, I. P., \& Yamin, M. (2016). Siaset Fakultas Teknik Universitas Halu Oleo Dengan Menggunakan Sistem Penunjang Keputusan Metode Weighted Product Dan Sistem Informasi Geografis Berbasis Web. semanTIK, Vol.2, No.2, 65-73.

Rosa, A., \& Shalahuddin, M. (2013). Rekayasa Perangkat Lunak Terstruktur dan Berorientasi Objek. Bandung: Penerbit Informatika.

Solikhin, Rachmatullah, R., \& Riyanto, E. (2014). Pengembangan Sistem Informasi Registrasi Seminar, Workshop dan Pelatihan Menggunakan Metode System Development Life Cycle Model Waterfall (Studi Kasus STMIK Himsya Semarang), 4-8.

Sugiarti, Y. (2013). Analisis \& Perancangan UML (Unified Modelling Language) Generated VB. 6. Jakarta: Penerbit Graha IImu.

Sulistiyono, R. P. (2013). Website Development Using CMS (Joomla!-Wordpress). Bandung: Penerbit Nuansa Cendekia. 